\title{
Formulation of Mixed Probiotic Starter Culture for the Production and Extending the Shelf Life of Ergo (Spontaneously Fermented Milk)
}

\author{
Zerihun Asefa $^{1} \quad$ Anteneh Tesfaye $^{2} \quad$ Asnake Desaleng $^{3} \quad$ Tadessa Daba $^{3}$ \\ 1.Ethiopian Institute of Agricultural Research P. O. Box 2003. Addis Ababa, Ethiopia \\ 2.Addis Ababa University, Biotechnology Institute, PO Box 314, Addis Ababa, Ethiopia \\ 3.Addis Ababa University, Department of Microbial, Cellular and Molecular Biology P. O. Box 1176. Addis \\ Ababa, Ethiopia
}

\begin{abstract}
Probiotics are live microorganisms that confer a beneficial effect on the host when administered in enough amounts and in appropriate conditions. They can modulate the intestinal biome of the consumer. This study aimed to formulate probiotic starter culture and evaluating their antagonistic effect on some foodborne pathogens such as Escherichia coli, Staphylococcus aureus, Salmonella Typhimurium, and Listeria monocytogen. The study also aimed at evaluating the impact of the formulated starter cultures on the sensory acceptability and shelf life of ergo. Accordingly, seven lactic acid bacteria L. rhamnosus(GB-15), L. paracasei(SB-7), L. reuteriG-23), L. sake(BB60), L. curvatus(NZ-44) L. plantarum(NN-33), L. casei(BZ-26) and one yeast species S. cerevisiae (Y-72) were used. The selected isolates were combined in different proportions to formulate the starter cultures for the production of ergo. Nine formulations were made in different proportions based on the compatibility of the isolates. Ergo prepared in this study was observed to have a pH of $3.99-4.38$ with titratable acidity of $0.60-0.97$ after 48 hrs of fermentation. The formulate F2 (GB-15,G-23, NZ-44, BB-33, NZ-26, Y-72) and F6 (GB-15, BB-60,NZ44,NZ-26,Y-72) showed complete inhibition against all the test pathogens after $48 \mathrm{hrs}$ of fermentation, except for Staphylococcus aurous with F6. The ergo products with starter culture formulate F2, F4 and, F6 were found to have better overall sensory acceptability with a mean score value of $3.75,3.56,3.73$, and 4.03/5.00, respectively. Ergo products with formulate F2and F6 had a shelf life of more than 12 days and 15 days, respectively, at an ambient temperature of $18-24^{\circ} \mathrm{C}$. Our starter culture formulates in addition to retaining the typical sensory quality of homemade ergo, they improved the shelf life and safety of the product.
\end{abstract}

Keywords: Bio-protective; Ergo; Probiotics; Shelf life; Starter Culture

DOI: $10.7176 / \mathrm{JNSR} / 13-6-02$

Publication date:March $31^{\text {st }} 2021$

\section{Introduction}

Milk is one of the major livestock products in urban, peri-urban, and pastoral dairy systems in Ethiopia. Due to its short shelf life, it is consumed immediately or processed into more stable products. Milk is processed into different products in the world to improve the organoleptic characteristics, shelf life, and safety of the products (Akabanda et al., 2010). Milk fermentation and processing are the oldest traditional practices in Ethiopia (Redda, 2001), among which, ergo is the most common homemade traditionally fermented product. It is analogs to the commercial yogurt, and can be consumed as it is, or further processed into other dairy products, mainly ayib (cottage cheese), whey, and butter. The fermentation process of ergo takes place as a result of the activities of natural microbial flora present in the milk or those introduced from the surrounding. During fermentation of ergo, the raw milk is not pasteurized but simply kept at an ambient or warmer temperature for $24-48 \mathrm{hrs}$. Since ergo is fermented spontaneously at home without a defined starter culture, it is subjected to variable organoleptic and nonreproducible characteristics, short shelf life, and higher spoilage risks. In addition, there is no practice of pasteurizing fresh milk before fermentation to ergo, as it delays the spontaneous fermentation process (Gonfa et al., 2001). This makes the safety of traditionally produced ergo uncertain due to the use of poor sanitation of raw milk for processing (Gurmessa, 2015).

Probiotics are live microorganisms that confer a beneficial effect on the host when administered in enough amounts (FAO/WHO, 2001). Probiotic microorganisms are important for (i) improving intestinal health by regulating microbiota, (ii) stimulating the development of the immune system, (iii) synthesizing and enhancing the bioavailability of nutrients, reducing symptoms of lactose intolerance, (iv) reducing the risk of other diseases and (v) providing special therapeutic or prophylactic properties such as reducing cancer and controlling serum cholesterol levels (Shandilya \& Sharma, 2017).

The development of starter culture with bio-preservative and probiotic qualities in addition to fermentation capability may help to produce bio-preserved, reproducible, and safe products. This study was, therefore, aiming at developing bio-protective probiotic starter culture for the production of safe, consistent, and standard ergo with extended shelf life. 


\section{Materials and methods}

Description of the study area

The study was conducted at Holeta Agricultural Research Center from November 2017 to June 2018. The center is located at $29 \mathrm{Km}$ west of Addis Ababa, the capital city of Ethiopia, 9"00 N latitude and $38^{\circ} 30 \mathrm{E}$ longitude and at an altitude of 2391 (2004) m a.s.l.

\section{Candidate lactic acid and yeast isolates}

Seven lactic acid bacteria species $L$. rhamnosus(GB-15), L. paracasei(SB-7), L. reuteriG-23), L. sake(BB-60), $L$. curvatus(NZ-44) L. plantarum(NN-33), L. casei(BZ-26) and one yeast species $S$. cerevisiae (Y-72) used in this study were obtained from the Ethiopian National Agricultural Biotechnology Research Center (NABRC). They were previously isolated from traditional fermented ergo and kocho (smashed and fermented enset pseudo-stem) samples collected from different agro-ecologies of Ethiopia. These are screened based on their antimicrobial effects, fermentation capabilities, and probiotic attributes.

\section{Compatibility test of isolates}

To formulate bio-protective and probiotic consortia of these microbes, the compatibility of the isolates was determined by cross streaking each isolate against the other on a modified MRS agar plate (modified by decreasing glucose content to $1 \%$ and yeast extract to $2 \%$ ) and incubating at $37{ }^{\circ} \mathrm{C}$ for $48 \mathrm{hrs}$. Their growth patterns were recorded after $48 \mathrm{hrs}$ of incubation. The isolates showing the best compatibility were chosen for the starter formulations.

\section{Formulation of starter culture}

Each pure isolates having $10^{6} \mathrm{CFU} / \mathrm{ml}$ was mixed in different proportions in a flask containing $800 \mathrm{ml}$ of pasteurized whole milk to determine a suitable combination for the production of ergo using design expert software version 7.0.0/2005. Nine combinations/ formulations of the starter cultures were made in different proportions. Table 1: Proportion of LAB and yeast isolates in formulations ( $\%$ of the milk).

\begin{tabular}{|c|c|c|c|c|c|c|c|c|c|}
\hline Formulates & $\begin{array}{c}\text { GB-15 } \\
\text { (\%) }\end{array}$ & $\begin{array}{l}\text { SB-7 } \\
(\%)\end{array}$ & $\begin{array}{l}\text { G-23 } \\
(\%)\end{array}$ & $\begin{array}{c}\text { BB-60 } \\
(\%) \\
\end{array}$ & $\begin{array}{c}\text { NZ-44 } \\
\mathbf{( \% )}\end{array}$ & $\begin{array}{c}\text { BB-33 } \\
\mathbf{( \% )}\end{array}$ & $\begin{array}{c}\text { NZ-26 } \\
\mathbf{( \% )}\end{array}$ & $\begin{array}{l}\text { Y } 72 \\
(\%)\end{array}$ & $\begin{array}{c}\text { Total } \\
\text { starter } \\
\text { inoculates }\end{array}$ \\
\hline $\mathrm{F} 1$ & - & 0.5 & 0.5 & 0.5 & - & 0.5 & 0.5 & 2.5 & $5 \%$ \\
\hline $\mathrm{F} 2$ & 1.50 & - & 0.75 & - & 0.75 & 0.50 & 1.0 & 0.50 & $5 \%$ \\
\hline F3 & 0.75 & 0.75 & - & 2.25 & - & 1.5 & - & - & $5 \%$ \\
\hline $\mathrm{F} 4$ & 0.75 & 0.75 & 0.75 & 0.75 & 0.5 & - & 1.25 & 0.25 & $5 \%$ \\
\hline F5 & 1.5 & 0.5 & 0.5 & 0.5 & 0.5 & 0.5 & 0.5 & 0.5 & $5 \%$ \\
\hline F6 & 1.5 & - & - & 0.5 & 2 & & 0.5 & 0.5 & $5 \%$ \\
\hline F7 & - & 2.75 & 0.75 & 0.75 & - & 0.75 & - & - & $5 \%$ \\
\hline F8 & 0.5 & 0.5 & 0.5 & - & 0.5 & 2.5 & - & 0.5 & $5 \%$ \\
\hline F9 & 0.75 & 0.75 & 0.5 & - & 2.5 & - & 0.5 & - & $5 \%$ \\
\hline Control A & & & & - & & & & & $5 \%$ \\
\hline
\end{tabular}

Control $A=$ commercially available starter culture; $F 1, F 2 \ldots F 9=$ formulated starter culture; $L A B=L A B$ isolate; $G B-15, S B-7, G-23, B B-60, N Z-44, B B-33$ and $N Z-26=$ LAB isolates; $Y 72=$ yeast isolates.

\section{Preparation of ergo using the formulated starter culture Sample preparation}

A fresh cow milk sample of 10 liters was collected using carefully cleaned and sterilized vessels from bulk milk produced at Holeta Agricultural Research farm and filtered with sterilized cheesecloth. The milk was pasteurized at $85{ }^{\circ} \mathrm{C}$ for 30 minutes.

\section{Homogenization}

The milk was homogenized using a homogenizer (model FG30043, Germany) after pasteurization to prevent the formation of a cream layer on the surface of the product during incubation. Then, it was cooled to $40-45^{\circ} \mathrm{C}$ and $5 \%$ of the formulated starter culture was added (Karagozlu et al., 2017). It was incubated at a temperature of $37 \pm$ $2{ }^{0} \mathrm{C}$ for $4-6 \mathrm{hrs}$ to ferment, after which the ergo was ready for consumption.

\section{Sensory evaluation of the products}

Eleven ergo products (nine produced using different formulated starter cultures and two controls) were prepared for sensory analysis. The ergo samples were randomized and coded with three-digit numbers and separately served at 7 to $10^{\circ} \mathrm{C}$ in plastic cups. A test description form comprising of five sensory attributes was given to each assessor. The sensory attribute namely, color, flavor, odor, texture, and overall acceptability were rated using a five-point 
hedonic scale. Ten semi-trained panelists of adult males and females were identified as assessors and provided with glasses of water and, instructed to rinse their mouth with water during testing each sample.

\section{Antagonistic test against some foodborne pathogens}

Test organisms, namely, Escherichia coli ATCC 43895, Staphylococcus aureus ATCC 25923, Salmonella Typhimurium ATCC 14802 and Listeria monocytogen ATCC 15313, were obtained from Holeta Dairy Research Laboratory.

A co-culturing method was used to test the antagonistic ability of each formulate on the test pathogens. Starter culture of $6 \log \mathrm{CFU} / \mathrm{ml}$ was inoculated into $300 \mathrm{ml}$ of pasteurized skim milk and $3 \mathrm{log} \mathrm{CFU} / \mathrm{ml}$ of each test pathogen separately were inoculated in a flask and incubated at $37^{\circ} \mathrm{C}$ for $48 \mathrm{hrs}$ in an anaerobic jar.

Each test pathogen was separately inoculated in $300 \mathrm{ml}$ of unpasteurized milk in triplicate to give final inoculums of $3 \log \mathrm{CFU} / \mathrm{ml}$ as a control. Samples of $1 \mathrm{ml}$ from each co-cultured and control sample were drawn right before incubation and after 24 and $48 \mathrm{hrs}$ of incubation. Aliquotes from appropriate dilutions were separately pour plated on selective media. The characteristic of the colony formed was evaluated and enumerated after incubation at $37 \pm 2^{\circ} \mathrm{C}$ for $24-48 \mathrm{hrs}$. When the growth of test pathogens was not detected $(<1 \log \mathrm{CFU} / \mathrm{ml}), 1 \mathrm{~g}$ of each sample was enriched nutrient broth in $9 \mathrm{ml}$ at $37 \pm 2{ }^{\circ} \mathrm{C}$ for $24 \mathrm{hrs}$. The enriched samples were streaked on the respective media and the plates were checked for the absence of perceptive colonies of target test pathogen due to complete inhibition.

\section{Estimation of the shelf life of the products}

Ergo products made using different formulated starter cultures were stored at an ambient temperature. The sensory test was done on the first day and every three days until the products were unfit for a sensory test. The shelf life cut-off point was 3.5, as it was indicated by (Gimenez et al., 2012). The sensory shelf life of the products was estimated using a natural log of overall acceptability versus storage time linear regression and first-order kinetic reaction to getting rate constant $(\mathrm{K})$. Using rate constant $\mathrm{K}$, the initial overall sensory acceptability $\left(\mathrm{A}_{0}\right)$ and quality limit $\left(\mathrm{A}_{t}\right)$ of an overall mean score, the shelf life of the product was calculated following Arrhenius first order reaction equation(Tsironi et al., 2009).

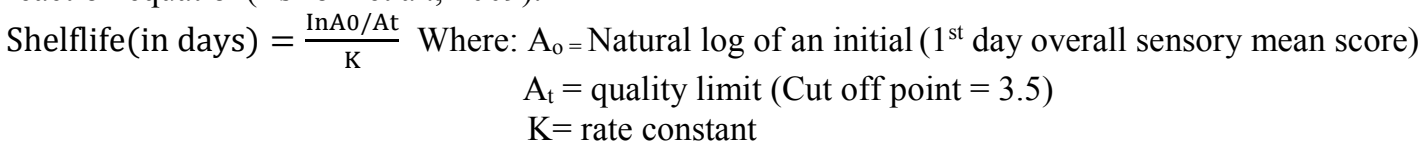

\section{Statistical analysis}

Data obtained from the antagonistic effects of the formulated starter cultures on test organisms were analyzed using ANOVA, at $\alpha=0.05$ levels of significance using SAS ver. 9.3, 2014. The mean difference between treatments was tested using Duncan Multiple Range tests. Data obtained from the sensory analysis was analyzed using repeated measure ANOVA (Treatment- by -panelist design), which blocks the variability due to panelist from the variability due to treatment.

\section{Result and Discussions}

In this study, the lowest $\mathrm{pH}$ values of ergo fermented by different starter culture combinations were 3.99 for ergo fermented with formulate F2 at $48 \mathrm{hrs}$. The $\mathrm{pH}$ of the products was decreasing (became more acidic) and titratable acidity was increasing as the time of fermentation extended from $24 \mathrm{hrs}$ to $48 \mathrm{hrs}$ (Table 2), due to fermentation of lactose in the milk. In line with this, it has been reported that these two parameters together with other metabolites enhance the antagonistic effect of formulates on foodborne pathogens (Pundir et al., 2013). 
Table 2: The antagonistic effect of formulates against food borne pathogens

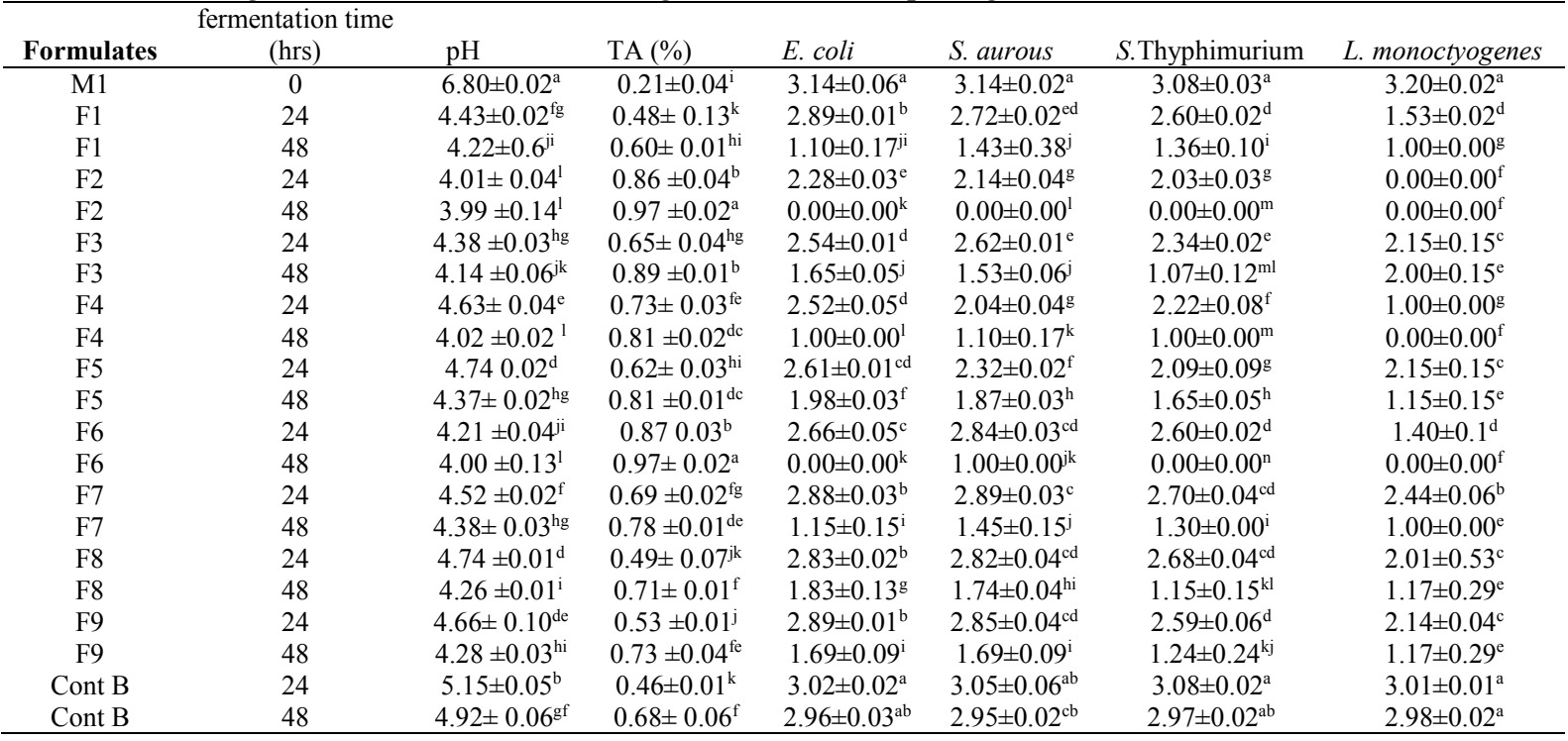

All values are mean $\pm S D$ in triplicate; Means followed by same letter(s) with in a column are not significantly different at $p=0.05$; Cont $B=$ control fermented ergo, $M 1=$ fresh raw milk before inoculation; $F 1, F 2 \ldots F 9=$ ergo product; TA = titratable acidity.

In this study, all formulate co-cultured with the test organisms in fermented milk showed an antagonistic effect on the test pathogens (Table 2). The most inhibitory effect against each of the four test pathogens (E. coli ATCC $43895, S$. aureus ATCC 25923, $S$. Typhimurium ATCC 14802, and L. monoctyogenes ATCC 15313) was exhibited by F2 and F6 formulates in the course of fermentation of ergo for 48 hrs. Formulates F2 and F6 showed complete inhibition of E. coli ATCC 43895 after $48 \mathrm{hrs}$ of fermentation. During $24 \mathrm{hrs}$ of fermentation, E. coli count was reduced to $2.52 \log$ CFU/ml in ergo fermented with formulate F4. Similarly, Tesfaye et al., (2011) have reported that mixed LAB culture eliminated E. coli after 36 hrs of co-culturing (Kasimoglua et al., (2004) have also reported that $10^{6} \mathrm{cfu} \mathrm{g}^{-1}$ of E. coli $\mathrm{O} 157: \mathrm{H} 7$ was eliminated after $48 \mathrm{hrs}$ incubation in acidophilus yogurt. Mufandaedza et al., (2006) have also reported that the population of E. coli decreased by $2 \log$ units during fermentation of milk with L. biovar. In general, the formulated starter cultures in the present study had a better antagonistic effect on E. coli in the course of fermentation of ergo. This antagonistic effect might be due to the production of antimicrobial metabolites, reduction of the $\mathrm{pH}$ in addition to the effects of other organic acids.

Standard S. aureus ATCC 25923 co-cultured with formulate F2 and F6 was eliminated after 48 hrs of fermentation. Following F2 and F6, formulate F4 showed the higher antagonistic effect on S. aureus, reducing its population to $1.0 \log \mathrm{CFU} / \mathrm{ml}$ after $48 \mathrm{hrs}$. In agreement with this, Piyawan et al., (2006) reported that LAB cocultured with $S$. aureus ATCC 25923 reduced the population of $S$. aureus by $8 \log$ units after 24 hrs. In general, the results of this study indicate that formulated starter cultures have a better inhibitory effect on the pathogens, which might be due to the synergistic antagonistic effects of the starter isolates.

Similar to E. coli and S. aureus, S. Typhimurium ATCC 14802 co-cultured with F2 and F6 was eliminated after $48 \mathrm{hrs}$ of fermentation of ergo. Formulate F4 and F3 following F2 and F6, showed a better antagonistic effect on $S$. Typhimurium after 48 hrs. Tesfaye et al., (2011), also reported a similar result, indicating that $S$. Typhimurium DT104 co-cultured with mixed LAB culture was eliminated after $48 \mathrm{hrs}$ when stored at an ambient temperature. A supportive result of reduction of $S$. Typhimurium by $3.2 \log$ units while being co-cultured with probiotic organisms in MRS medium was also reported by (Tharmaraj and Shah, 2009).

L. monoctyogenes ATCC 15313 co-cultured with F2 was eliminated after 24 and 48 hrs of fermentation. Formulate F6 reduced the population of test pathogen to $2.60 \mathrm{log}$ CFU/ml after $24 \mathrm{hrs}$ and completely inhibited after $48 \mathrm{hrs}$ of co-culturing in fermenting milk. In a related study 0.8 and $1.3 \log \mathrm{CFU} / \mathrm{ml}$ reduction of $L$. monoctyogenes co-cultured with LAB for 12 and $24 \mathrm{hrs}$ in fermented milk was reported by (Ashenafi, 2015).

Sensory attributes, mainly color, flavor, and texture, of yogurt are important quality characteristics of the product and are generally considered the most critical indicators of consumer preferences(Singh-Ackbarali \& Maharaj, 2014). Flavors with respect to odor and color have an overwhelming influence on the overall acceptability of milk products (Bibiana et al., 2014). In the present study, ergo products prepared using different starter culture formulate were found to have a significant difference $(\mathrm{p}<0.05)$ in color $($ Table 2$)$. The results showed higher color mean score values of 3.85 and 3.77 for F6 and F2, respectively. These products had a glossy surface appearance without excessive whey. Ergo product F2 (3.74), F3 (3.81), and F6 (3.67) exhibited significantly $(\mathrm{P}<0.05)$ higher mean score values for flavor which ranged between 2.55 for F9 and 3.81 for F3 on 5 points hedonic scale. It has 
been reported that the lactic acid content of the product, as well as its diacetyl and ethyl acetate contents, are factors that influence the flavor of yogurt (Beshkova et al., 2003). Acidity also influences the quality attributes of yogurt such as flavor, texture, whey syneresis, and shelf life.

Table 3: Sensory characteristics of ergo fermented with different starter cultures

\begin{tabular}{|c|c|c|c|c|c|}
\hline \multicolumn{6}{|c|}{ Score values for sensory characteristics (Mean score \pm SD) } \\
\hline Product & Color & Flavor & Odor & Texture & $\begin{array}{l}\text { Overall } \\
\text { acceptability }\end{array}$ \\
\hline $\mathrm{F} 1$ & $3.04 \pm 0.59^{\mathrm{cdb}}$ & $2.91 \pm 0.54^{\mathrm{cdb}}$ & $3.11 \pm 0.54^{\mathrm{cd}}$ & $3.38 \pm 0.73^{\mathrm{ab}}$ & $3.02 \pm 0.53^{\mathrm{cb}}$ \\
\hline $\mathrm{F} 2$ & $3.77 \pm 0.58^{\mathrm{a}}$ & $3.74 \pm 0.44^{\mathrm{a}}$ & $3.72 \pm 0.42^{\mathrm{ab}}$ & $3.79 \pm 0.45^{\mathrm{a}}$ & $3.75 \pm 0.47^{\mathrm{a}}$ \\
\hline F3 & $3.16 \pm 0.67^{\mathrm{cb}}$ & $3.81 \pm 0.87^{\mathrm{a}}$ & $3.23 \pm 0.37^{\mathrm{cdb}}$ & $3.42 \pm 0.48^{\mathrm{ab}}$ & $3.39 \pm 0.46^{\mathrm{ab}}$ \\
\hline F4 & $3.59 \pm 0.26^{\mathrm{ab}}$ & $3.5 \pm 0.37^{\mathrm{ab}}$ & $3.59 \pm 0.47^{\mathrm{cab}}$ & $3.42 \pm 0.38^{\mathrm{ab}}$ & $3.56 \pm 0.37^{\mathrm{a}}$ \\
\hline F5 & $3.14 \pm 0.66^{\mathrm{cb}}$ & $3.19 \pm 0.56^{\mathrm{cab}}$ & $3.82 \pm 0.47^{\mathrm{a}}$ & $3.78 \pm 0.41^{\mathrm{a}}$ & $3.38 \pm 0.56^{\mathrm{ab}}$ \\
\hline F6 & $3.85 \pm 0.47^{\mathrm{a}}$ & $3.67 \pm 0.48^{\mathrm{a}}$ & $3.65 \pm 0.42^{\mathrm{ab}}$ & $3.74 \pm 0.56^{\mathrm{a}}$ & $3.73 \pm 0.43^{\mathrm{a}}$ \\
\hline F7 & $3.13 \pm 0.18^{\mathrm{cb}}$ & $3.32 \pm 0.22^{\mathrm{cab}}$ & $3.60 \pm 0.21^{\mathrm{cab}}$ & $3.55 \pm 0.58^{\mathrm{a}}$ & $3.35 \pm 0.12^{\mathrm{ab}}$ \\
\hline F8 & $2.78 \pm 0.28^{\mathrm{cd}}$ & $2.78 \pm 0.26^{\mathrm{cd}}$ & $2.85 \pm 0.59^{\mathrm{d}}$ & $2.92 \pm 0.25^{b}$ & $2.80 \pm 0.37^{\mathrm{c}}$ \\
\hline F9 & $2.55 \pm 0.42^{\mathrm{d}}$ & $2.55 \pm 0.50^{\mathrm{d}}$ & $3.09 \pm 0.26^{\mathrm{cd}}$ & $2.97 \pm 0.31^{b}$ & $2.73 \pm 0.39^{c}$ \\
\hline Cont A & $3.34 \pm 0.56^{\mathrm{cab}}$ & $3.22 \pm 0.76^{\mathrm{cab}}$ & $3.57 \pm 0.64^{\mathrm{cab}}$ & $3.76 \pm 0.34^{\mathrm{a}}$ & $3.43 \pm 0.65^{\mathrm{ab}}$ \\
\hline Cont B & $3.31 \pm 0.65^{\mathrm{cab}}$ & $2.92 \pm 0.61^{\mathrm{cdb}}$ & $3.39 \pm 0.34 \mathrm{c}^{\mathrm{ab}}$ & $2.99 \pm 0.54^{\mathrm{b}}$ & $3.20 \pm 0.47^{\mathrm{b}}$ \\
\hline
\end{tabular}

All values are Mean score \pm SD of triplicate data; F1, F2 ... F9 = Ergo product; Cont A commercial yogurt; Cont $B=$ control fermented ergo; Values followed by the same letter(s)within a column are not significantly different at $p=0.05$.

Variability in titratable acidity among products might entail variability in the flavor of the ergo product (Beshkova et al., 2003). Production of the lactic acid band and other flavor enhancing compounds by the starter culture may also influence the flavor of the final product. Generally, in the current study, ergo products of F1(3.02, F3(3.39) F7(3.35), F8 (2.80), and F9 (2.73) had low overall acceptability with mean score values below average, 3.5. The texture of yogurt can be influenced by milk composition, dry matter content, heating, homogenization, the type of starter culture, incubation temperature, cooling, and storage time (Karsheva et al., 2013). In this regard, there was variation in the texture of ergo prepared with those different starter cultures formulates, with mean score values ranging from 2.92 to 3.79 . This variability in texture could also be attributed to differences in acid values of the products. Product F2 and F6 showed relatively higher texture mean score values of 3.75 and 3.73, respectively (Table 2). In line with this, Kesenkas et al., (2017) have reported that titratable acidity has a significant effect on the texture of yogurt; as texture increase with the increasing acidity of the products. Bibiana et al., (2014) also reported an increase in firmness of yogurt as the $\mathrm{pH}$ decreased. Overall acceptability score reflects the score value given to all sensory parameters (Narayana \& Gupta, 2013). Accordingly, ergo product F2, F6 (3.75) and F4(3.56) had significantly $(\mathrm{p}<0.05)$ higher mean score values for overall sensory acceptability as shown in Table 2, which has a direct relationship with the mean score of flavor, odor, texture and color Macciola et al. (2008).

The shelf life of ergo as evaluated by sensory parameter after stored at an ambient temperature $\left(18-24^{\circ} \mathrm{C}\right)$, was found to range from 15 days for product F6 to 6 days for product F1 (Table 3). Product F2 had a shelf life of 12 days, which was a higher value next to product F6. This shows that all the products have longer shelf life than that of naturally fermented ergo (2-4 days) Gonfa et al., (2001) stored at an ambient temperature. This variation in shelf life might be due to differences in antimicrobial substance in the starter cultures

Table 4: Sensory shelf life of ergo stored at an ambient temperature of $18-24^{\circ} \mathrm{C}$

\begin{tabular}{|c|c|c|c|c|c|}
\hline Product & $\begin{array}{l}\text { Quality } \\
\text { criteria }\end{array}$ & $\begin{array}{l}\text { Storage } \\
\text { temp }\end{array}$ & $\begin{array}{l}\text { Quality } \\
\text { limit }\end{array}$ & $\mathbf{R}^{2}$ & $\begin{array}{l}\text { Estimated shelf life (in } \\
\text { days) }\end{array}$ \\
\hline F1 & & & 3.5 & 0.99 & 6 \\
\hline F2 & $\Xi$ & & 3.5 & 0.97 & 12 \\
\hline F3 & శ్ & & 3.5 & 0.94 & 9 \\
\hline F4 & 8 & & 3.5 & 0.97 & 10 \\
\hline F5 & ש्थ & ○ & 3.5 & 0.98 & 7 \\
\hline F6 & $\bar{\pi}$ & $\stackrel{\leftrightarrow}{4}$ & 3.5 & 0.95 & 15 \\
\hline F7 & $\stackrel{0}{0}$ & $\infty$ & 3.5 & 0.99 & 8 \\
\hline F8 & 0 & & 3.5 & 0.98 & 7 \\
\hline F9 & 5 & & 3.5 & 0.97 & 8 \\
\hline Cont A & है & & 3.5 & 0.98 & 7 \\
\hline Cont B & & & 3.5 & 0.94 & 6 \\
\hline
\end{tabular}

cont $A=$ ergo from commercial supermarket; cont $B=$ spontaneously fermented ergo, $R^{2}=$ coefficient of determination; F1, F2...F9 = ergo products made with formulated starter cultures. 
Conclusions

This study demonstrated that formulates F2(GB-15, G-23, NZ-44,BB-33,NZ-26,Y-72) and F6(GB-15, BB-60, NZ-44, NZ-26,Y-72) had better antagonistic effect on common foodborne pathogens. The formulates were able to reduce or inhibit foodborne pathogens mainly E. coli, S. aureus, S. Typhimurium, and L. monoctyogenes in the course of fermentation of ergo. These formulated starter cultures extended the shelf life of ergo from 6 days to 15 days when stored at ambient temperature $\left(18-24^{\circ} \mathrm{C}\right)$ while it is maximum of 4 days in naturally fermented ergo. Therefore, the result of this study indicates that using these formulated starter cultures would enhance the keeping quality of ergo with more, consumer acceptability. Moreover, it can be concluded that ergo, which is consumed raw if fermented with these starter cultures would serve as a vehicle for the provision of probiotics to consumers.

\section{Conflicts of Interest}

The authors declare that there is no conflicts of interest in the publication of this paper.

\section{Acknowledgments}

This project is supported by Addis Ababa University, Department of Microbial, Cellular and Molecular Biology, and Ethiopian Institute of Agricultural Research.

\section{References}

Akabanda, F., Owusu-Kwarteng, J., K.Glover, R. L., \& Tano-Debrah, K. (2010). Microbiological characteristics of Ghanaian traditional fermented milk product, Nunu. Nature and Sci., 8(9), 178-187.

Ashenafi, M. (2015). The fate of Listeria monocytogenes During the Souring of Ergo, a Traditional Ethiopian Fermented Milk. J. Dairy Sci., 77(3), 696-702.

Beshkova, D. M., Simova, E. D., Frengova, G. I., Simov, Z. I., \& Dimitrov, Z. P. (2003). Production of volatile aroma compounds by kefir starter cultures. Int.Dairy J., 13, 529-535.

Bibiana, I., Joseph, S., \& Amove, J. (2014). Physicochemical, microbiological, and sensory evaluation of yogurt sold in Makurdi metropolis. Afri. J.of Food Sci.\& and Techn., 5(6), 129-135.

FAO/WHO. (2001). Expert Consultation on Evaluation of Health and Nutritional Properties of Probiotics in Food Including Powder Milk with Live Lactic Acid Bacteria. Expert Consultation, October, 1-34.

Giménez, A., Ares, F., \& Ares, G. (2012). Sensory shelf-life estimation: A review of current methodological approaches. FRIN, 49(1), 311-325.

Gonfa, A., Foster, H. A., \& Holzapfel, W. H. (2001). Field survey and literature review on traditional fermented milk products of Ethiopia. Int.J.Food Microb., 68, 173-186.

Gurmessa Terfa. (2015). Microbiological quality and impact of hygienic practices on raw cow's milk obtained from pastoralists and market. The case of Yabello District, Borana zone. Global J.Food Scie. \&Techn., 3(2), $153-158$.

Karsheva, M., Paskov, V., Tropcheva, R., R.Georgieva, \& Danova, S. (2013). Physiochemical Parameters and Rheological properties of yogurts during the storage. J. Chemical Techn. \& Metallurgy, 48(5), 483-488.

Kasımoglu, A., M, G., \& S., A. (2004). Probiotic white cheese with Lactobacillus acidophilus. Int.Dairy J., 14, 1067-1073.

Kesenkas, H., Karagozlu, C., Yerlikaya, O., Ozer, E., Akpinar, A., \& Akbulut, N. (2017). Physicochemical and sensory characteristics of winter yogurt produced from mixtures of cow's and goat's milk. J. Agri. Sci., 23, 53-62.

Macciola, V., Candela, G., and De Leonardis, A. (2008). Rapid gas-chromatographic method for the determination of diacetyl in milk, fermented milk, and butter. Food Con. 19: 873-878.

Mufandaedza, J., Viljoen, B. C., Feresu, S. B., \& Gadaga, T. H. (2006). Antimicrobial properties of lactic acid bacteria and yeast-LAB cultures isolated from traditional fermented milk against pathogenic Escherichia coli and Salmonella enteritidis strains. Int.J. Food Microb., 108, 147-152.

Narayana, N. M. N. K., \& Gupta, V. K. (2013). Physical, Textural, and sensory attributes of plain set yogurt made employing ultrafiltration technique as affected by titratable acidity during incubation. Third International Symposium, 1, 19-24.

Pundir, R. K., Rana, S., Kashyap, N., \& Kaur, A. (2013). Probiotic potential of lactic acid bacteria isolated from food samples : an in vitro study. 3(03), 85-93.

Redda, T. (2001) Small scale milk marketing and processing in Ethiopia proceeding of the south. workshop on smallholder dairy production and marketing constraints, Addis Ababa, Ethiopia.

Shandilya, U. K., \& Sharma, A. (2017). Functional foods and their benefits : an overview. J. Nutr Health \& Food Eng, 7(4), 353-356.

Singh-Ackbarali, D., \& Maharaj, R. (2014). Sensory Evaluation as a Tool in Determining acceptability of innovative products developed by Undergraduate students in Food Science and technology at The University of Trinidad and Tobago. J.Curr.Teach, 3(1), 9-27. 
Tesfaye, A., Mehari, T., \& Ashenafi, M. (2011). Inhibition of some foodborne pathogens by pure and mixed LAB cultures during fermentation and storage of ergo, a traditional Ethiopian fermented milk. ARPN J. Agr. Biol.Sci., 6(4), 13-19.

Tharmaraj, N., \& Shah, N. P. (2009). Antimicrobial effects of probiotics against selected pathogenic and spoilage bacteria in cheese-based dips. Int. Food Res. J., 16, 261-276.

Tsironi, T., Dermesonlouoglou, E., Giannakourou, M., \& Taoukis, P. (2009). Shelf life modeling of frozen shrimp at variable temperature conditions. LWT - Food Scie. \&Techn., 42(2), 664-671.

Voravuthikunchai, S. P., Bilasoi, S., \& Supamala, O. (2006). Antagonistic activity against pathogenic bacteria by human vaginal lactobacilli. Anaerobe, 12, 221-226. 